\title{
Elevated plasma endothelin in patients with diabetes mellitus
}

\author{
K. Takahashi, M. A. Ghatei, H.-C.Lam, D.J.O'Halloran and S. R.Bloom \\ Department of Medicine, Royal Postgraduate Medical School, Hammersmith Hospital, London, UK
}

\begin{abstract}
Summary. Plasma concentrations of endothelin, a vasoconstrictor peptide released from vascular endothelial cells, have been measured by radioimmunoassay in 100 patients with diabetes mellitus and 19 healthy subjects. The plasma immunoreactive-endothelin concentrations were found to be greatly raised in the patients with diabetes $(1,880 \pm 120 \mathrm{fmol} / 1$, mean $\pm \mathrm{SEM})$ compared with the healthy subjects $(540 \pm 50$ $\mathrm{fmol} / 1, p<0.005)$. The elevation of immunoreactive-endothelin could not be explained by secondary changes in blood pressure or renal disease and did not correlate with the presence of diabetic retinopathy, duration of diabetes mellitus, fasting blood glucose or serum fructosamine. Fast protein liquid chromatographic analysis of the diabetic plasma immu-
\end{abstract}

noreactive-endothelin showed three forms, one in a very big molecular weight position, one intermediate and one in the position of endothelin-1 itself. No material appeared in the positions of endothelin-2 and 3. Chromatographic analysis of normal plasma showed only the big molecular weight peak while material in the endothelin $-1,2$ or 3 positions was below detection. The elevation of endothelin in diabetic patients may be a marker of, and further exacerbate, their vascular disease.

Key words: Endothelin, radioimmunoassay, diabetes mellitus, fast protein liquid chromatography, endothelial cell, angiopathy.
Angiopathy is a major complication in diabetes mellitus [1, 2]. Endothelial cell damage is suspected to occur in diabetic patients and may be one important cause of angiopathy [3].

Endothelin-1 is a potent vasoconstrictor peptide, which is thought to be synthesized by endothelial cells. It was originally isolated, and its structure characterised, from the conditioned medium of porcine aortic endothelial cells [4]. It is now known that there are three endothelin genes in the human genome (endothelin-1, 2 and 3 genes) $[5,6]$.

The presence of immunoreactive-endothelin in normal human plasma $[7,8]$ and increased plasma immunoreactive-endothelin level in patients with uraemia $[9,10]$ has been described. However, there are no reports of the possible changes from normal of plasma immunoreactive-endothelin levels in diabetes mellitus.

To help clarify the relationship between plasma endothelin and diabetic angiopathy, we measured plasma immunoreactive-endothelin concentrations in patients with diabetes mellitus and investigated the relationship between plasma immunoreactive-endothelin concentrations and blood pressure, spot urinary microalbumin, diabetic retinopathy, duration of diabetes mellitus, fasting blood glucose and serum fructosamine in these patients.

\section{Subjects and methods}

\section{Subjects}

We studied plasma immunoreactive-endothelin concentrations in 100 patients with diabetes mellitus (16 with Type 1 (insulin-dependent) diabetes and 84 with Type 2 (non-insulin-dependent) diabetes) and 19 normal subjects ( 11 male and 8 female, $20-65$ years old) by radioimmunoassay. Informed consent was obtained from each subject. All subjects had normal renal function (serum creatinine levels $<125 \mu \mathrm{mol} / \mathrm{l}$ ). Blood samples were obtained from a subcutaneous vein in the forearm, collected into heparinized tubes containing aprotinin (400 KIU/ml blood) (Bayer, FRG), centrifuged at room temperature, and the plasma separated and stored at $-20^{\circ} \mathrm{C}$ until extracted.

Fasting blood glucose was measured by a glucose oxidase method. Spot early morning urine samples were collected and urinary microalbumin was measured by the Technicon RA Systems microalbumin method (ID-2478-D88). Serum fructosamine was measured with the Technicon RA-1000 analyser [11]. Blood pressure was estimated in the supine position and the presence of diabetic retinopathy was assessed by ophthalmoscopic examination by diabetic ophthalmologists.

The Table 1 summarizes the clinical characteristics of $100 \mathrm{pa}-$ tients with diabetes and 19 normal subjects. In 84 patients with Type 2 diabetes, one patient had a past history of cerebral infarction, four patients had past histories of myocardial infarction and five pa- 


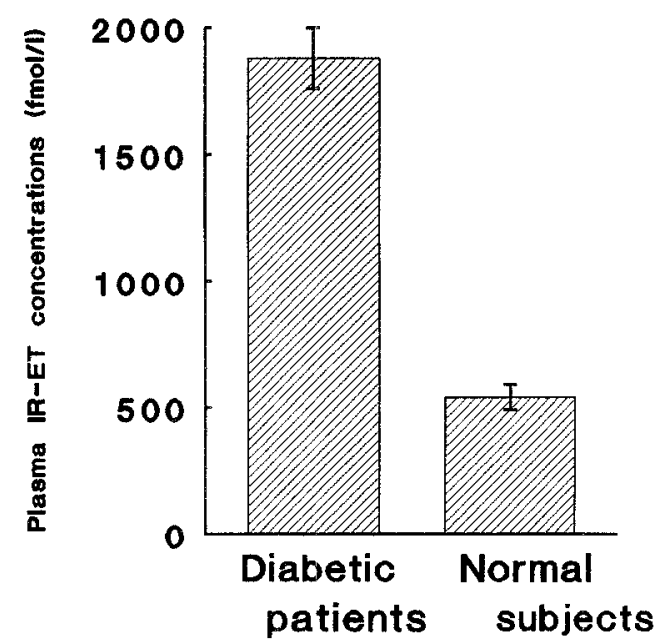

Fig 1. Mean \pm SEM of plasma immunoreactive-endothelin concentrations in 100 patients with diabetes mellitus and 19 normal subjects. IR-ET: immunoreactive endothelin

tients were having treatment for angina pectoris. No cerebral vascular disease or coronary vascular disease was found in 16 patients with Type 1 diabetes.

\section{Extraction procedures and radioimmunoassay}

Plasma samples were extracted by Sep-Pak C18 cartridges (Waters Associates, Milford Mass, USA) following Sep-Pak activation by $10 \mathrm{ml}$ of $100 \%$ acetonitrile, $10 \mathrm{ml}$ of $100 \%$ methanol and then $10 \mathrm{ml}$ of $4 \%$ (volume/volume (v/v)) acetic acid. Three mls of each plasma sample was acidified with $2 \mathrm{ml}$ of $4 \%$ acetic acid and loaded onto the cartridge, and the cartridge washed with $10 \mathrm{ml}$ of $4 \%$ acetic acid. Immunoreactive-endothelin was eluted with $2 \mathrm{ml}$ of $60 \%$ (v/v) acetonitrile/water containing $0.026 \mathrm{~mol} / \mathrm{l}$ ammonium acetate.

The eluate was dried in a Savant vacuum centrifuge, the resulting pellet reconstituted with assay buffer $\left[60 \mathrm{mmol} / 1 \mathrm{PO}_{4}\right.$ buffer, $\mathrm{pH} 7.4$ containing $10 \mathrm{mmol} / \mathrm{l}$ EDTA, $7 \mathrm{mmol} / \mathrm{l}$ sodium azide and $0.3 \%$ (weight/volume) bovine serum albumin] and the aliquot assayed in singlet. The recovery of peptide following this extraction procedure was determined by adding synthetic endothelin- 1 to plasma [ 5 fmol endothelin/ml plasma and $25 \mathrm{fmol}$ endothelin $/ \mathrm{ml}$ plasma yielded $72 \pm 14 \%$ and $102 \pm 20 \%$ (mean $\pm \mathrm{SD}, n=7$ ) recovery, respectively].

Antiserum to endothelin-1 was raised by injecting synthetic endothelin-1 (Nova Biochem, Nottingham UK) conjugated with bovine serum albumin by the diazo technique [12] into rabbits. The antiserum was used at a final dilution of 1:28,000. Synthetic endothelin-1 (Peptide Institute, Osaka, Japan) was used as standard and for iodination with $\mathrm{Na}^{125} \mathrm{I}$ by the chloramine $\mathrm{T}$ method [13]. The iodinated endothelin-1 was purified by high performance liquid chromatography as previously described [14]. After 3 days incubation at $4^{\circ} \mathrm{C}$, antibody-bound and free fractions were separated by charcoal adsorption of the free fraction.

The sensitivity of this assay was $0.5 \mathrm{fmol} / \mathrm{tube}$ or $250 \mathrm{fmol} / \mathrm{lindi}$ vidual plasma sample at $95 \%$ confidence. The assay showed $40 \%$ cross reaction with endothelin- 2 and $60 \%$ with endothelin-3 (Peptide Institute), but no cross reaction with human atrial natriuretic peptide, neuropeptide $\mathrm{Y}$, substance $\mathrm{P}$, vasoactive intestinal peptide, peptide histidine methionine, glucagon, angiotensin II or ACTH. Intra- and interassay coefficients of variation were $12 \%(n=9)$ and $19 \%(n=7)$, respectively.

\section{Chromatography}

Fractionation of the immunoreactive-endothelin from the plasma of diabetic patients and normal subjects was carried out by fast protein liquid chromatography using a high resolution reverse phase $5 / 5$ (Pep Rpc HR 5/5) C-18 column (Pharmacia, Uppsala, Sweden). Pooled diabetic and pooled normal plasmas $(n=3)$ were extracted by Sep-Pak C18 cartridges, reconstituted in water containing $0.1 \%$ $(\mathrm{v} / \mathrm{v})$ trifluoroacetic acid and centrifuged for $15 \mathrm{~min}$ in a microfuge. The supernatants were loaded onto the column, which was first equilibrated with $15 \%(\mathrm{v} / \mathrm{v})$ acetonitrile in water [each with $0.1 \%$ $(\mathrm{v} / \mathrm{v})$ trifluoroacetic acid]. After injection of the samples, the column was eluted with a gradient of acetonitrile from $15 \%$ to $35 \%(\mathrm{v} / \mathrm{v})$ in water over $1 \mathrm{~h}$ at $1 \mathrm{ml}$ per min per fraction. Samples of each fraction were dried in a Savant vacuum centrifuge, reconstituted in assay buffer and assayed.

\section{Stability of endothelin in human blood.}

To examine the stability of endothelin in human blood, endothelin-1 2 and 3 were incubated ( $2 \mathrm{pmol} / \mathrm{ml}$ blood) in mixed normal blood containing aprotinin ( $400 \mathrm{KIU} / \mathrm{ml}$ blood) at room temperature for 0 ,

Table 1. Clinical characteristics of 100 patients with diabetes mellitus and 19 normal subjects

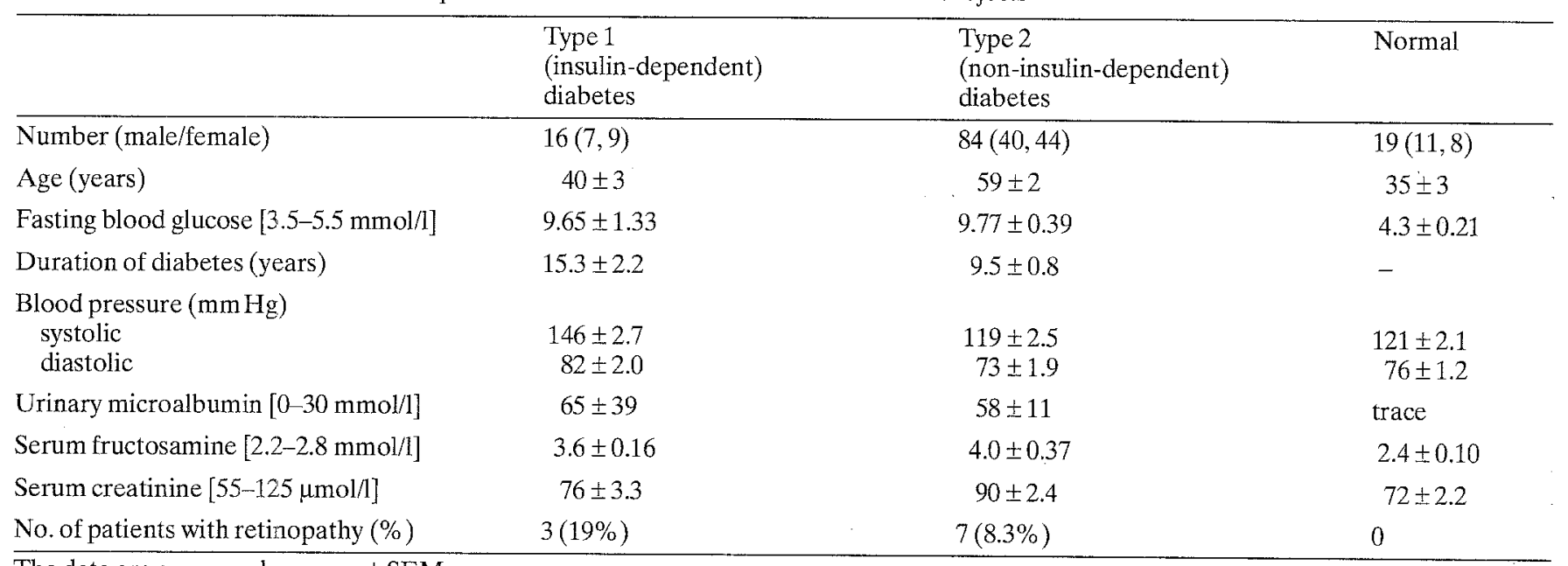

The data are expressed as mean \pm SEM.

The values in [ ] show the normal range. 

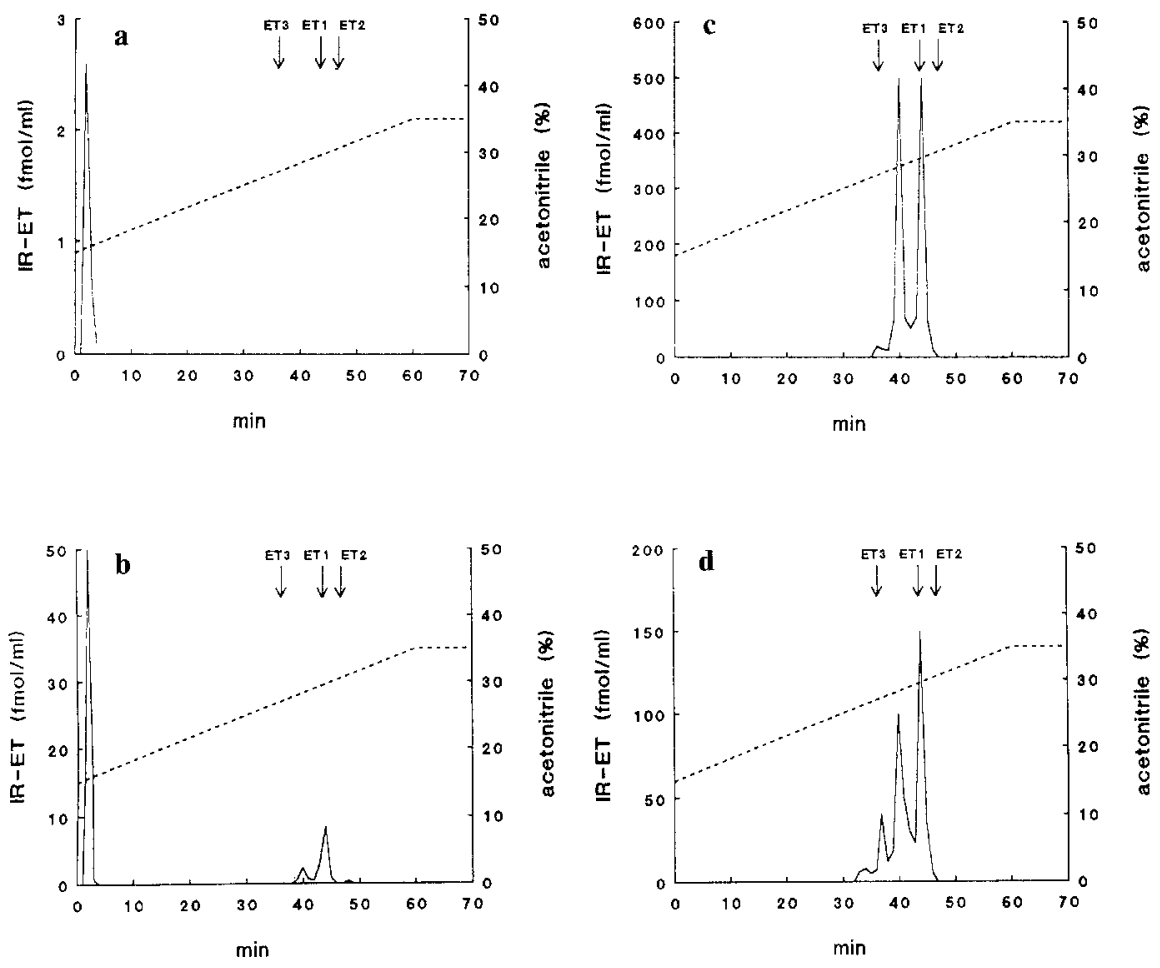

Fig. 2 a-d. Fast protein liquid chromatography of immunoreactiveendothelin in a) a pooled normal plasma extract, b) a pooled diabetic plasma extract, c) endothelin-1 mixed in normal blood but not incubated, d) endothelin-1 incubated in normal blood at room temperature for 24 h. IR-ET: immunoreactive endothelin. ET1, ET2 and ET3: the elution positions of endothelin-1, 2 and 3 , respectively
1, 8 and $24 \mathrm{~h}$. Blood samples were then centrifuged and separated, and immunoreactive-endothelin in plasma was measured by radioimmunoassay following fast protein liquid chromatography after extraction by Sep-Pak C18 cartridges.

\section{Statistical analysis}

The plasma immunoreactive-endothelin concentrations were expressed as mean \pm SEM. Analysis of variance was used to compare the plasma immunoreactive-endothelin concentrations among the groups. The relationship between plasma immunoreactive-endothelin concentrations and fasting blood glucose, mean blood pressure, urinary microalbumin, duration of diabetes mellitus and serum fructosamine in diabetic patients was analysed by linear regression. Two diabetic patients were receiving diuretics because of heart failure and 17 patients were on anti-hypertensive treatment, so these 19 patients were excluded from the analysis of this relationship.

\section{Results}

The mean plasma immunoreactive-endothelin concentrations in 100 patients with diabetes mellitus was 1,880 $\pm 100 \mathrm{fmol} / 1$ (Type 1: 2,090 $\pm 280 \mathrm{fmol} / 1, n=16$ and Type 2: $1,840 \pm 130 \mathrm{fmol} / \mathrm{l}, n=84$ ), both values were significantly higher than those in 19 normal subjects $(540 \pm 50 \mathrm{fmol} / \mathrm{l})(p<0.005)$ (Fig. 1$)$.

There were no significant correlations between plasma immunoreactive-endothelin concentrations and fasting blood glucose $(r=0.086, p>0.1, n=81)$, mean blood pressure $(r=0.12, p>0.1, n=81)$, urinary microalbumin $(r=0.0062, p>0.1, n=81)$, duration of diabetes mellitus $(r=0.108, p>0.1, n=81)$ and serum fructosamine $(r=$ $-0.086, p>0.1, n=81)$ in patients with diabetes mellitus. Seventeen diabetic patients treated with anti-hyperten- sives showed higher plasma immunoreactive-endothelin concentrations $(2,340 \pm 420 \mathrm{fmol} / \mathrm{l})$ than those without anti-hypertensives, but this difference was not statistically significant $(p>0.1)$. Plasma immunoreactive-endothelin concentrations in diabetic patients with all grades of background retinopathy as detected by simple ophthalmoscopy $(2,330 \pm 430 \mathrm{fmol} / 1, n=10)$ were higher than those in patients without such apparent retinopathy $(1,840 \pm 130 \mathrm{fmol} / \mathrm{l}, n=90)$ but again this difference was not statistically significant $(p>0.1)$. Plasma immunoreactive-endothelin concentrations in 10 Type 2 diabetic patients with cerebral or coronary artery diseases $(2,010 \pm 310 \mathrm{fmol} / \mathrm{l})$ were not significantly different from those in the other diabetic patients $(p>0.1)$.

Fast protein liquid chromatography revealed that immunoreactive-endothelin in diabetic plasma eluted in three positions; one major peak occurred just after the void volume, one peak after the position of endothelin-3 but before the position of endothelin-1 and one peak in the position of endothelin-1 (Fig. 2b). No immunoreactive-endothelin was demonstrated in the positions of endothelin-2 and 3. The fast protein liquid chromatography profiles obtained on normal plasma samples showed one peak which eluted at the void volume position and corresponded with the major peak seen in the diabetic plasma profiles (Fig. 2a). The recovery of immunoreactive-endothelin in plasma extract from the column was 101\%.

Endothelin-1 in human blood at room temperature was unstable. The total content of immunoreactive-endothelin in the blood with exogenously added endothelin-1 did not change for up to $8 \mathrm{~h}$ following addition but decreased to about $50 \%$ of the basal value at $24 \mathrm{~h}$. However, fast protein liquid chromatography showed that exogenous endothelin-1 generated two other forms of immu- 
noreactive-endothelin (Fig. $2 \mathrm{~d}$ ) and this was apparent even at zero time (Fig. $2 \mathrm{c}$ ).

Endothelin-2 in human blood at room temperature was very stable. The total content of immunoreactiveendothelin in the blood with exogenously added endothelin-2 did not change for up to $24 \mathrm{~h}$ following addition. Fast protein liquid chromatography showed that immunoreactive-endothelin in all four blood samples with exogenously added endothelin-2 at different incubation times eluted in an identical position to endothelin-2 (data not shown).

Endothelin-3 in human blood at room temperature was also stable. The total content of immunoreactiveendothelin in the blood with exogenously added endothelin-3 did not change for up to $8 \mathrm{~h}$ following addition but decreased to about $60 \%$ of the basal value at $24 \mathrm{~h}$. Fast protein liquid chromatography showed that immunoreactive-endothelin in all four blood samples with exogenously added endothelin-3 at different incubation times eluted in an identical position to endothelin-3 (data not shown).

\section{Discussion}

We developed a sensitive radioimmunoassay for the estimation of human plasma endothelin-1, with a lower detection limit of $250 \mathrm{fmol} / \mathrm{l}$. Plasma immunoreactive-endothelin concentrations in normal subjects were found to be similar to those previously reported by others $[7,8]$. A recent study failed to detect immunoreactive-endothelin in the plasma of non-insulin dependent diabetes [10]. In contrast, we found greatly increased plasma immunoreactiveendothelin concentrations in patients with diabetes. Our assay is about six times more sensitive than that of Koyama et al. [10] (their sensitivity was $3.5 \mathrm{pg} / \mathrm{ml}=$ about $1,400 \mathrm{fmol} / 1)$. Therefore, we could detect plasma immunoreactive-endothelin concentrations both in normal subjects and diabetic patients, and compare them.

Chromatographic analysis of the circulating endothelin was difficult owing to the low concentrations involved but by use of fast protein liquid chromatography three clearly separate forms were demonstrated. The largest peak in diabetic plasma and the only peak in normal plasma was found in the void volume. This void volume peak was not seen after incubation of synthetic endothelin-1,2 and 3 in blood suggesting that it was not an artefact produced from endothelin-1,2 or 3. Its greater surface hydrophilicity may indicate a larger folded molecule, perhaps a precursor of endothelin that is more slowly cleared from the circulation [15]. Endothelin-2 and 3 were stable in blood but exogenously added endothelin- 1 generated two immunoreactive peaks eluting several fractions earlier than synthetic endothelin-1 on fast protein liquid chromatography. Endothelin-1 has methionine at position 7, which is easily oxidised, therefore these immunoreactive peaks eluting earlier may represent endothelin-1 with methionine sulphoxide. In the diabetic plasma detectable material was found in the exact position of endothelin- 1 but not 2 or 3 . An additional peak was noted in the position of material generated when pure synthetic endo- thelin- 1 was added to blood and this may have arisen by a similar process from endothelin-1 released endogenously. It is noteworthy that while total immunoreactive-endothelin is some threefold raised in the diabetic subjects, material behaving like endothelin-1 itself was below the detection limit in healthy control subjects. This suggests the elevation of true endothelin- 1 in diabetic patients may be relatively very much greater than the total immunoreactivity figures would suggest.

Endothelin-1 has very potent vasoconstrictor actions [4] and can stimulate endothelial cell growth [16]. Endothelin- 1 could be produced not only by large vessels but also small vessels such as retinal microvessels [17]. Endothelin receptors are present in cultured rat aortic smooth muscle cells [18] and cultured bovine retinal pericytes [17]. We suspect that increased immunoreactive-endothelin in diabetic plasma, presumably derived from endothelial cells, reflects endothelial cell damage and may in turn be related to the complications of diabetes. The elevated endothelin concentrations did not appear to be secondary to hypertension or renal disease, nor was any relationship found between endothelin levels and fasting blood glucose, serum fructosamine, duration of diabetic mellitus or diabetic retinopathy. The pathophysiological role(s) of endothelin in plasma of diabetes needs further investigation. It is known to be an important vascular stimulant [16] and may thus play a role in the genesis of diabetic complications.

In conclusion, development of a sensitive radioimmunoassay for endothelin in human plasma has revealed a highly significant endothelin elevation in diabetic subjects which may relate to diabetic endothelial cell damage and in turn be an important background factor in diabetic vascular complications.

Acknowledgements. We are grateful to Dr. S.J.Gilbey and Mrs. K. Davies for their critical reading and helpful discussions.

\section{References}

1. Kannel WB, McGee DL (1979) Diabetes and cardiovascular disease. The Framingham study. JAMA 241: 2035-2038

2. Jarrett RJ, McCartney P, Keen H (1982) The Bedford survey: ten year mortality rates in newly diagnosed diabetics, borderline diabetics and normoglycaemic controls and risk indices for coronary heart diseases in borderline diabetics. Diabetologia 22 79-84

3. Porta M, Selva ML, Molinatti P, Molinatti GM (1987) Endothelial cell function in diabetic microangiopathy. Diabetologia 30 ; 601-609

4. Yanagisawa M, Kurihara H, Kimura S, Tomobe Y, Kobayashi M, Mitsui Y, Yazaki Y, Goto K, Masaki T (1988) A novel potent vasoconstrictor peptide produced by vascular endothelial cells. Nature 332: 411-415

5. Yanagisawa M, Inoue A, Ishikawa $T$, Kasuya $Y$, Kimura S, Kumagaye S, Nakajima K, Watanabe TX, Sakakibara S, Goto K, Masaki T (1988) Primary structure, synthesis, and biological activity of rat endothelin, an endothelium-derived vasoconstrictor peptide. Proc Natl Acad Sci USA 85: 6964-6967

6. Inoue A, Yanagisawa M, Kimura S, Kasuya Y, Miyauchi T, Goto K, Masaki T (1989) The human endothelin family: three structurally and pharmacologically distinct isopeptides predicted by three separate genes. Proc Natl Acad Sci USA 86: 2863-2867 
7. Ando A, Hirata Y, Schichiri M, Emori T, Marumo F (1989) Presence of immunoreactive endothelin in human plasma. FEBS Lett 245: 164-166

8. Hartter E, Woloszczuk W (1989) Radioimmunoassay of endothelin. Lancet I: 909

9. Totsune K, Mouri T, Takahashi K, Ohneda M, Sone M, Furuta T, Saito T, Yoshinaga K (1989) Immunoreactive endothelin (IRET) in plasma of hemodialysis patients. Kidney Int 35: 321 (Abstract)

10. Koyama H, Tabata T, Nishzawa Y, Inoue T, Morii H, Yamaji T (1989) Plasma endothelin levels in patients with uraemia. Lancet I: $991-992$

11. San-Gil F, Schier GM, Moses RG, Gan IET (1985) Improved estimation of fructosamine, as a measure of glycated serum protein, with the Technicon RA-1000 analyzer. Clin Chem 31: 2005-2006

12. Senyk G, Nitecki DE, Spitler L, Goodman JW (1972) The immune response to glucagon in conjugated form. Immunocytochemistry 9: 92-110

13. Hunter WM, Greenwood FC (1962) Preparation of iodine-131 labelled human growth hormone of high specific activity. Nature 194: 495-496

14. Kanse SM, Ghatei MA, Bloom SR (1989) Endothelin binding sites in porcine aortic and rat lung membrane. Eur $\mathbf{J}$ Biochem 182: $175-179$

15. Itoh Y, Yanagisawa M, Ohkubo S, Kimura C, Kosaka T, Inoue A, Ishida N, Mitsui Y, Onda H, Fujino M, Masaki T (1988) Cloning and sequence of CDNA encoding the precursor of a human endothelium-derived vasoconstrictor peptide, endothelin: identity of human and porcine endothelin. FEBS Lett 231: 440-444

16. Kimura S, Kurihara H, Sugiyama T, Takaku F, Yazaki Y (1988) Endothelin stimulates c-fos and c-mys expression and proliferation of vascular smooth muscle cells. FEBS Lett 238: 249-252

17. Takahashi K, Brooks RA, Kanse SM, Ghatei MA, Kohner EM, Bloom SR (1989) Production of endothelin 1 by cultured bovine retinal endothelial cells and presence of endothelin receptors on associated pericytes. Diabetes 38: 1200-1202

18. Hirata Y, Yoshimi H, Takata S, Watanabe TX, Kumagai S, Nakajima K, Sakakibara S (1988) Cellular mechanism of action by a novel vasoconstrictor endothelin in cultured rat vascular smooth muscle cells. Biochem Biophys Res Commun 154:868-875

Received: 23 August 1989

and in revised form: 5 December 1989

Prof. S.R. Bloom

Department of Medicine

Francis Fraser Laboratory 2nd Floor

Royal Postgraduate Medical School

Hammersmith Hospital

Du Cane Road

London W12 ONN

UK 